\title{
UMA INVERSÃO DIDÁTICA NOS CURSOS DE PÓS-GRADUAÇÃO
}

\section{A didactic inversion in the courses of post-graduation}

\author{
Lilian Anna Wachowicz \\ D outora em Educação pela PUC-SP, Pós-doutora em Educação pela UAB, Universidade \\ Autônoma de Barcelona, CEEPR, Curitiba, PR - Brasil, e-mail: ilian.bendhack@ gmail.com
}

\section{Resumo}

Nosso estudo apresenta a formação continuada de professores como uma das possibilidades do ensino em nível de Pós-Graduação, tomando na forma de exemplaridade o Programa de D esenvolvimento Educacional do Paraná - PDE, que é de formação continuada para professores em exercício e pertencentes ao quadro de magistério do Estado. O s professores PDE não são inseridos em cursos de pós-graduação lato ou stricto sensu. Cursam disciplinas ofertadas em nível de graduação, dentre outras atividades de inserção acadêmica. 0 que nos leva a exemplificar que a formação continuada pelo PDE são os princípios pedagógicos, de gestão e didáticos, que representam a nosso ver uma inversão didática sendo esta uma das condições favoráveis à transformação da prática profissional, talvez a mais importante. Com base em Bachelard, por sua epistemologia histórica; Habermas, por sua teoria da ação comunicativa; e Vygotsky, pela categoria de mediação na sua teoria de aprendizagem, nossa proposição de inversão didática pretende priorizar a vivência dos atores sociais na educação escolar, como sendo o ponto de partida e de chegada da reflexão coletiva, com a orientação das universidades conveniadas.

Palavras-chave: Formação continuada. Pós-G raduação. Inversão didática.

Rev. D iálogo Educ., Curitiba, v. 9, n. 26, p. 29-45, jan./ abr. 2009 


\begin{abstract}
Our study presents continuous teacher training as one of the possibilities of post-graduate teaching taking as a model the Educational Development Program of Parana -EDP, which offers continuous in-service training for teachers who belong to the teaching staff of the state schools of Parana. The EDP teachers are not inserted in post-graduate courses either in Master's degree study or in Doctor's degree study. They take disciplines offered at graduation level and other academic insertion activities. What leads us to clarify the continuous education through the EDP is its pedagogical principles -teaching and managerial - which represent from our point of view a didactic inversion which is one of the conditions that favor the transformation of the professional practice, perhaps the most important of them. Based on Bachelard's historical epistemology; on Habermas's theory of communicative action; and on Vygotsky's mediation category in its theory of learning, the didactic inversion we propose aims at priorizing the life experience of the social actors in education, as departure and arrival points of the collective reflection, with the guidance of the participating universities.
\end{abstract}

Keywords: Continued formation. Post-Graduation. Didactic inversion.

Conhecido como PDE, o Programa de Desenvolvimento Educacional foi criado pelo governo do Paraná pelo D ecreto $n .{ }^{-0} 4482$, de 14 de março de 2005, que atribuía ao programa o objetivo de aperfeicoamento permanente e qualificação sistemática do professor da rede estadual de educação básica do Paraná e, como meta qualitativa, a melhoria do processo ensino-aprendizagem nas escolas públicas estaduais.

Foi implantado ao final de 2006, quando o primeiro processo seletivo foi realizado e foram abertas 1.200 vagas, distribuídas em dezessete áreas: Língua Portuguesa, Matemática, G eografia, História, Ciências, Educação Física, Educação Artística, Física, Q uímica, Biologia, Filosofia, Sociologia, Pedagogia, Línguas Estrangeiras Modernas, Educação e Trabalho, G estão E scolar e Educação Especial. O mesmo D ecreto declara que a qualificação profissional do professor no PDE dar-se-á por meio de estudos orientados nas modalidades presencial e à distância em programas de pós-graduação de instituições de ensino superior e que considerem a experiência profissional do professor, bem como pela aplicação do conhecimento relativo à educação básica e profissional.

Rev. Diálogo Educ., Curitiba, v. 9, n. 26, p. 29-45, jan./ abr. 2009 
Em 2007 uma resolução do Secretário de Estado da Educação, de n.. 4341, normatiza a operacionalização do PD E, tendo em vista as disposições contidas na Lei Complementar no 103, de 15 de março de 2004, no D ecreto nํㅡ 4482/ 2005 e no Decreto no 3149/ 2004 (PARANÁ 2004):

Art. 1ㅇ 0 Programa de Desenvolvimento Educacional PDE é um programa de formação continuada, implementado pela Secretaria de Estado da Educação, em parceria com a Secretaria de Estado da Ciência, Tecnologia e Ensino Superior e Instituições de Ensino Superior.

Art. 2ㅇ O Programa de D esenvolvimento Educacional PDE assume características diferenciadas dos cursos de pós-graduação tradicionais, considerando seu direcionamento para a melhoria das práticas docentes e de gestão escolar, através do aperfeiçoamento dos professores da Educação Básica.

Art. 3ㅇ 0 PDE será desenvolvido no período de 02 (dois) anos, a partir de março de cada ano, sendo organizado em 04 (quatro) períodos, com carga horária total de 952 horas (novecentas e cinqüenta e duas horas).

Em agosto de 2008 foi institucionalizado por um D ecreto Estadual, após o que foram assinados convênios com as Universidades públicas do Estado, nos quais várias medidas de favorecimento do programa foram tomadas, tais como 0 aumento do número de vagas anuais para inscrição no programa e abertura de vagas para concurso de ingresso de professores nas universidades estaduais, visando ampliar o número de orientadores da pesquisa que constitui o trabalho final do aluno/ professor matriculado no programa.

É uma política pública que pretende estabelecer o diálogo entre os professores da Educação Superior e os da Educação Básica, através de atividades teórico-práticas orientadas, tendo como resultado a produção de conhecimento e mudanças qualitativas na prática escolar da escola pública paranaense.

O Programa de D esenvolvimento Educacional - PDE está integrado às atividades da formação continuada em Educação. Em consequência das negociações com o Sindicato dos professores do Paraná (APP-Sindicato) 0 programa visa, também, promover o professor para o Nível III da Carreira, conforme previsto no Plano de Carreira do Magistério Estadual, Lei Complementar no 103, de 15 de março de 2004. Essas negociações deram ao PDE uma condição material e concreta para reforçá-lo, sendo de inscrição voluntária para todos os professores efetivos da rede estadual. O s inscritos passam por um processo seletivo, tendo em vista haver sempre mais candidatos do que vagas.

Rev. D iálogo Educ., Curitiba, v. 9, n. 26, p. 29-45, jan./ abr. 2009 
O s professores selecionados atualmente cursistas têm pós-graduação lato sensu, na sua totalidade (especialização em sua área de conhecimento). Muitos já fizeram Mestrado e outros, inclusive, D outorado. 0 programa tem revelado ser de seu interesse, para além do interesse material, porque se caracteriza como sendo formação continuada desenvolvida a partir de sua prática profissional. 0 objetivo específico do programa é proporcionar aos professores da rede pública estadual subsídios teórico-metodológicos para o desenvolvimento de ações educacionais sistematizadas e que resultem em redimensionamento de sua prática. O PDE se destina aos professores do Quadro Próprio do Magistério - Q PM, que se encontram no Nível II, Classe 11 da Tabela de Vencimentos do Plano de Carreira. A ascensão para o Nível III da carreira pode ser feita pelo PDE.

No Artigo 8º, o decreto de sua criação apresenta o processo de seleção em várias etapas: 1) avaliação do domínio da norma culta da língua portuguesa, de caráter eliminatório; 2) avaliação detítulos, de caráter classificatório, considerada maior titulação acadêmica obtida em nível de pós-graduação, sendo: 5 pontos para cada certificado de especialista, até 0 máximo de 10 pontos; 15 pontos para cada diploma de mestre, até 0 máximo de 30 pontos; e 30 pontos para o título de doutor, 3) avaliação da produção didático-pedagógicae científica, de caráter classificatório, sendo computados até 60 pontos para trabalhos e experiências sistematizadas no sistema educacional, eaté 10 pontos para a avaliação do memorial descritivo, nos termos do regulamento do PDE; 4) apresentação de projeto com programa de estudos e proposta de aplicação, de caráter classificatório, com indicação e anuência de professor orientador, que apresente titulação superior à do orientando e 5) entrevista para apresentação do projeto perante banca examinadora.

O Programa de D esenvolvimento Educacional - PDE tem oferecido cursos e atividades nas modalidades presencial e à distância e disponibilizado apoio logístico e meios tecnológicos para as atividades. 0 professor que ingressar no PD E terá garantido o direito a afastamento remunerado de 100\% de sua carga horária efetiva no primeiro ano e de $25 \%$ no segundo ano do Programa. Este afastamento foi regulamentado por uma Resolução Secretarial em 2007, conforme disposto no Art. 13 da Lei que institui a carreira do magistério no Paraná.

\section{Uma inversão didática}

D essa apresentação, que consta dos documentos oficiais do programa, podemos inferir quais são os princípios norteadores do trabalho, os quais nos levaram a selecionar esse programa como uma iniciativa para a formação continuada dimensionada no foco da prática profissional. Esses princípios são: uma dinâmica de trabalho na qual o ponto de partida não mais está no conhecimento sistematizado e sim no conhecimento da prática; sendo individualizado esse conhecimento da

Rev. Diálogo Educ., Curitiba, v. 9, n. 26, p. 29-45, jan./ abr. 2009 
prática, torna-se necessário adotar o procedimento didático da socialização dos conhecimentos, o que exige momentos coletivos de aprendizagem presencial; em seguida, as reflexões teóricas são conduzidas pelo professor na Universidade, quando entram as contribuições dos conhecimentos sistematizados nos livros e outros produtos culturais, aos quais os professores cursistas têm acesso; os grupos de trabalho realizam essa reflexão em parceria com o professor da Universidade e finalmente apresentam cada um a proposta de transformação possível de sua prática, na forma de sínteses elaboradas pelo grupo. Todo o conjunto de conhecimentos adquiridos durante o programa é incorporado no trabalho final, individual, de pesquisa, o qual deverá ser aplicado à prática profissional do professor cursista, desde 0 segundo ano do curso e defendido ao final dele.

O s princípios são: fontes de trabalho recolocadas na prática profissional; metodologia da sistematização coletiva dos conhecimentos ${ }^{1}$ e objetivos de transformação da prática. Trata-se de uma inversão didática frente ao procedimento tradicionalmente utilizado nos cursos de pós-graduação e na educação superior em geral, o qual tem como ponto de partida o conhecimento sistematizado, tomado como apoio para a pesquisa do conhecimento científico. Esse processo, que chamamos tradicional porque tem sido utilizado por um longo tempo desde a criação das Universidades como instituições sociais, tem marcadamente uma característica de ensino individualizado, o que vem gerando a dificuldade crescente do número de vagas para os alunos, candidatos a tais cursos. Especialmente no Brasil, cuja população pretende cada dia mais a formação em nível superior, as vagas são irrisórias diante do número de candidatos a cada curso. Também a legislação vem estimulando cursos de pós-graduação, lato e stricto sensu, mediante compensações salariais na própria universidade para seus profissionais e um sistema de avaliação desses mesmos profissionais com base em sua produção científica. No âmbito da Educação, a questão das vagas é mais aguda, por se tratarem de profissionais que atendem a um sistema monumental em termos quantitativos, sendo esses professores um contingente numerosíssimo.

A educação escolar é filha da cultura na qual está instituída. No caso brasileiro, essa cultura tem apresentado nos últimos dez anos grandes diferenças em relação aos tempos anteriores, sendo muito positivas algumas mudanças e outras muito negativas, no sentido de favorecerem ou não a instituição social da escola e seu principal objetivo, que é a conquista do conhecimento na sua melhor forma. A conquista do conhecimento é o que chamamos aprendizagem.

A metodologia da sistematização coletiva de conhecimentos foi criada pela Dra. Pura Lúcia O liver Martins, na sua Dissertação de Mestrado defendida e aprovada na UFMG em 1984 e divulgada por inúmeros cursos, sendo publicada no livro Didática teórica/ Didática prática, editado pela Loyola de São Paulo, em 1989.

Rev. D iálogo Educ., Curitiba, v. 9, n. 26, p. 29-45, jan./ abr. 2009 
Nesse ponto, é preciso conceituar a aprendizagem como sendo 0 processo pelo qual o pensamento estabelece relações entre os dados que lhe são apresentados como fontes e cria 0 significado do conjunto de tais relações. 0 processo se passa em nível de pensamento e ousamos dizer que somente pode desenvolver-se num coletivo de pessoas que tenham acesso às fontes e à metodologia apropriadas, coletivo esse formado em torno do objetivo comum da conquista do conhecimento. Quando esse processo é instituído com todos os cuidados necessários, não só o conhecimento transforma-se em pensamento, como também pode chegarà transformação do pensamento em sabedoria. $\mathrm{O}$ instrumento mais eficaz nesse processo é a reflexão expressa em argumentos e esta representa a primeira diferença na cultura dos tempos atuais e dos anteriores.

A reflexão necessita de palavras e de silêncio, ao mesmo tempo. As palavras que geram reflexão são aquelas carregadas de vivências, e não palavras vazias repetidas de autores de textos que foram escritos sem vivência. Também as imagens, as cenas, as animações são fontes carregadas de sentido. Quantas vezes assistimos a um filme, daqueles de fazer pensar, e então queremos conversar sobre ele, para compreendê-lo? Esse é o processo da aprendizagem, e por isso dizemos que ele necessita de um coletivo de pessoas que tenham o objetivo de aprender.

Nos tempos atuais, dificilmente encontramos pessoas com tempo disponível para a reflexão. Esta é uma operação mental que está caindo em desuso, por sua complexidade e pela necessidade de alimentá-la num coletivo de pessoas. A diferença positiva desse aspecto, entre os tempos atuais e os anteriores, é a quantidade das fontes e sua diversidade. Num tempo virtual, que é muito mais acelerado do que o tempo real, temos informações de todo tipo e num amplo espaço de compreensão. 0 mundo está dentro das casas, nas telas e nos sons que se tornaram acessíveis. Mas nosso cérebro evidentemente trabalha em tempo real e, ao filtrar tantas informações, precisa de um tempo para tornar a cabeça bem feita, ${ }^{2}$ que é muito diferente da cabeça cheia.

Outra grande dificuldade da escola nos tempos atuais são os problemas que se acentuaram com o crescimento das cidades e dos espaços urbanos: a violência tem chegado às salas de aula na forma de agressões verbais e de agressões físicas aos professores. 0 número de alunos que demanda a escolaridade aumentou tremendamente e as políticas públicas esbarram nos orçamentos insuficientes. A legislação busca formas de atender a essa demanda, e recentemente encontrou na educação à distância o filão para resolver a questão do espaço e do tempo para a aprendizagem. Milhares de sala de aula podem receber ao mesmo tempo a transmissão das fontes de informação disponíveis.

A expressão "cabeça bem feita" foi cunhada por Edgar Morin e divulgada em português brasileiro no livro A cabeça bem feita, 2000.

Rev. Diálogo Educ., Curitiba, v. 9, n. 26, p. 29-45, jan./ abr. 2009 
Mas se não houver em cada uma dessas salas um professor para dirigir o processo da aprendizagem, não haverá transformação da informação em conhecimento e muito menos a transformação do conhecimento em pensamento. D a sabedoria, não há para esse objetivo a menor condição de alimentá-la sem o processamento instituído da reflexão. A leitura de bons textos alimentava nos tempos anteriores esse processo. Mas as gerações mais jovens foram substituindo os livros pela internet, pelos hi-pods, pelas drogas e por outras fontes de sensações que tragam a adrenalina considerada necessária.

Estabeleceu-se então o mal-estar docente. Cunhada a partir de Freud e seu famoso livro 0 mal-estar da civilização, o mal-estar docente aparece como sintoma dos novos tempos e a fascinação do mundo dos conhecimentos vai se tornando incapaz de combatê-lo. Com esse título, surge o livro de Esteve (1999), com o subtítulo: a sala de aula e a saúde do professor. Com base em pesquisas realizadas na Espanha, o livro aponta a situação na qual se encontram os profissionais da educação escolar e indica as condições de seu trabalho como causadoras de estresse e ansiedade.

Um dos meios que podem ser utilizados para combater o mal-estar docente é a formação continuada comprometida com a sua prática profissional, porque 0 conhecimento tem 0 atributo de libertar nossa mente, assim que atingir o significado da situação. Por outro lado, a inversão didática, que é a nossa proposta, liberta o professor da carga pesada de ministrar aulas contando somente com sua memória e capacidade de transmissão. Amplia as possibilidades de fontes atualizadas e possibilita aos alunos o prazer da participação no processo.

O s programas de Pós-G raduação em Educação no Brasil iniciaram de certa forma essa inversão didática, ao congregarem alunos vindos de vários Estados para os grandes centros como Rio e São Paulo, inicialmente os únicos a ofertarem os cursos, ainda nos anos 70. Com a possibilidade de reunir os grupos de alunos uma vez por semana, o professor estabelecia cronogramas de leituras e o grupo ao encontrar-se trazia as contribuições na forma de participação espontânea, exercendo a leitura prévia um papel diretivo no foco da temática. 0 nível de conteúdo dos textos e o nível intelectual e profissional de cada participante determinavam a qualidade do debate.

Esse foi um início da inversão didática, posicionando-se o professor como diretor da aprendizagem do grupo, não maior do que quinze pessoas e, principalmente, indicando no cronograma de leituras as melhores produções disponíveis. Um passo à frente foi estabelecer como ponto de partida não o conhecimento sistematizado nesses textos apresentados na sua melhor forma, mas o conhecimento aplicado a situações vivenciadas pelos participantes com as leituras dos melhores textos, concomitantemente. 0 professor tem nessa inversão uma responsabilidade redobrada de leitura e produção científica, em nível de pós-

Rev. D iálogo Educ., Curitiba, v. 9, n. 26, p. 29-45, jan./ abr. 2009 
graduação. Ele e outros membros do grupo enquanto parceiros nessa luta pela conquista do conhecimento podem levar o processo de aprendizagem aos limites de suas capacidades em cada campo do conhecimento.

0 processo é instituído de forma a criar em cada sessão a possibilidade de atingir o grupo o limite máximo da reflexão. Não há como prever o que pode acontecer numa aula assim preparada.

Entendemos que o Programa de D esenvolvimento Educacional tem condições de realizar a inversão didática, ao congregar professores em exercício e colocar sua carga horária remunerada totalmente dedicada aos estudos em nível de pós-graduação, durante um ano e mais, durante $25 \%$ da carga horária de um segundo ano, com a orientação de professores das universidades. Primeiro, porque são professores em exercício profissional que têm a sua prática em nível de ponto de partida para uma reflexão coletiva, com o tempo necessário para exercê-la. E segundo, porque terão que retornar à sua prática ainda com a orientação dos professores da universidade e com o compromisso de apresentar em nível de pesquisa o projeto inicial de estudos no programa.

Os fundamentos teóricos dessa proposta didática encontram-se na epistemologia histórica de Bachelard, à qual chegamos após um percurso de alguns anos na busca das contribuições possíveis no campo da dialética, sendo esta a lógica que nos levou a colocar na realidade a prioridade epistemológica. No âmbito da teoria crítica da sociedade na qual se insere a instituição escolar, a teoria da ação comunicativa de Habermas nos fundamenta para a conceituação da educação como uma ação, na qual a linguagem exerce um papel fundamental. Completando o que chamamos um tripé que proporciona uma base firme para a compreensão da inversão didática, está uma das teorias cognitivas de aprendizagem, a de Vygotsky, que define a relação entre desenvolvimento e aprendizagem como sendo dialética e na qual a mediação da cultura é exercida pelo professor no grupo de alunos. Em todos os três fundamentos, a realidade vivenciada tem prioridade enquanto método gerador da reflexão coletiva.

Não se trata de uma realidade no sentido comum, mas da prática social, que é compreendida no âmbito mais amplo da construção da realidade pelo homem, sendo ele mesmo construído por essa realidade social. ${ }^{3} \mathrm{O}$ u seja, trata-se da realidade histórica.

Nesse sentido amplo, existe uma unidade entre o pensar e o agir, que é chamada por alguns autores como sendo a "práxis" . ${ }^{4}$ Por essa conceituação, a teoria e a prática não se separam, ainda que sejam distintas. Uma não existe sem a outra, numa

3 Ver BERGER; LUCKMANN, 1973.

4 Ver VÁSQUEZ, 1977.

Rev. Diálogo Educ., Curitiba, v. 9, n. 26, p. 29-45, jan./ abr. 2009 
situação de tensão, também chamada como sendo a relação de "pares dialéticos". Preferimos a palavra tensão, porque ela carrega as categorias de movimento e de conflito, presentes na epistemologia histónica. Equivocadamente, a relação teoria e prática é apresentada muitas vezes como sendo de articulação. Mas não se pode articular aquilo que existe junto, e se manifesta com seus componentes num todo que não se expressa quando apenas um dos componentes é tido como mais importante que 0 outro, ou existente sem 0 outro. Um bom exemplo seria o da eletricidade: há um estado de tensão entre dois polos, sem os quais não existirá o fenômeno da energia. No cotidiano, qualquer pessoa sabe que duas pilhas fazem funcionar os aparelhos mais simples, como uma lanterna, e que essas pilhas têm que ser colocadas na posição inversa uma da outra, para que haja a ligação: senão, a lanterna não acende.

No método didático também, a tensão entre os pares dialéticos tem que ser mantida sob cuidados extremos, senão a aprendizagem não ocorre. Essa tensão ${ }^{5}$ é apenas uma das condições para a aprendizagem. Sendo esta um movimento que se realiza na mente do aluno, a energia que passa entre seus neurônios pelas sinapses é que se revela a condição decisiva.

Voltando às tensões dialéticas, podemos dizer que teoria e prática são aspectos de um mesmo processo, atuando ambos ao mesmo tempo para que a prática social tenha significado. Este vem no âmbito da subjetividade, o que representa mais uma vez a importância do contexto cultural, que é determinante na seleção dos significados. Essa seleção não é realizada pelo sujeito individualmente, mas num contexto no qual o poder tem grande força diretiva. Um dos papéis da reflexão expressa em argumentos, ou seja, da racionalidade, é justamente dotar o sujeito da isenção possível na seleção dos significados impostos ao grupo social no qual ele vive e aprende. D esmistificar a realidade social é uma das tarefas mais complexas da aprendizagem, especialmente nos tempos atuais em que a força da comunicação de massa e da indústria cultural é manipulada pelo poder político.

A globalização como processo de dominação econômica tem sua mais perigosa expressão na dominação cultural, o ponto mais objetivo da colonização. No caso brasileiro, ${ }^{6}$ essa colonização provoca uma alienação cultural que é fatal para a educação escolar, quando não utilizada a reflexão expressa em argumentos, como o método didático necessário.

Por todas essas razões, a inversão didática é necessária, com o objetivo de criar as condições para 0 aluno aprender a pensar e motivar-se para aplicar 0 conhecimento na prática social. 0 conhecimento aplicado é o ponto de partida e

\footnotetext{
5 Ver WACHOWICZ, (1998).

6 Ver BOSI, 1992.
}

Rev. D iálogo Educ., Curitiba, v. 9, n. 26, p. 29-45, jan./ abr. 2009 
0 ponto de chegada nesse processo, sendo que 0 ponto de chegada já não é 0 mesmo de onde o pensamento partiu, mas está enriquecido pela reflexão com os indicadores da transformação desejada, como intencionalidade desde o início.

Os procedimentos adotados pelo PDE possibilitam ao aluno professor cumprir esse percurso: ao exigir o projeto de início, avalia a intencionalidade do processo. Um projeto de pesquisa, por outro lado, cumpre a condição de trazer ao ponto de partida a prática social profissional do aluno professor, na forma de conhecimento aplicado. Houve na História da Educação várias iniciativas no sentido de trazer o conhecimento aplicado como ponto de partida. Porém, essas iniciativas em geral representaram na prática pedagógica situações artificiais criadas para integrar no currículo os campos do conhecimento. A inversão didática agora proposta é de centrar na prática real, utilizando recortes dessa prática no âmbito profissional, o ponto de partida para a reflexão teórica e com base nos argumentos da racionalidade.

0 aspecto emocional, antes trazido na forma de motivação, éatendido como sendo a fonte de energia necessária para sustentar todo 0 processo, até 0 cumprimento efetivo do projeto, na sua volta à prática profissional, de onde partiu. Somente a realidade, ainda que recortada para cada projeto, tem esse poder de gerar e sustentar a reflexão: não é suficiente uma situação artificialmente imaginada, para conter os aspectos complexos das relações que se estabelecem entre os fatos, efetivamente apresentados em tempo real.

\section{A epistemologia histórica e as teorias da ação e da aprendizagem}

Para entender a proposta da abordagem do vasto campo do conhecimento como sendo o método necessário para tratá-lo como objeto do trabalho pedagógico, torna-se importante a compreensão da forma pela qual esse conhecimento se organiza na história recente da humanidade.

0 marxismo, o estruturalismo e o funcionalismo podem ser considerados como sendo as três correntes geradoras das interpretações da economia e da sociedade, que polarizaram o pensamento ocidental no século XX.

A pergunta central da racionalidade ocidental foi: Como analisar as condições de aparecimento e 0 efeito das relações que os homens travam entre si na produção material de sua existência, sob a lógica profunda do funcionamento e evolução das sociedades? (GODELIER, 1973, p. 45).

As três correntes opuseram-se às reduções simplistas do empirismo, do positivismo e do economicismo do século X IX, mas ao criticar essas reduções absorveram e superaram suas propostas. Para ficarmos apenas na tradicional

Rev. Diálogo Educ., Curitiba, v. 9, n. 26, p. 29-45, jan./ abr. 2009 
antropologia cultural americana, que teve influências marcantes no sistema educacional brasileiro, sedimentadas pela Lei Federal n.. 5692/ 71: (BRA SIL, 1971) o idealismo e o psicologismo presentes nela foram criticados nos anos 50 e os estudiosos que fizeram tais críticas declararam-se partidários de uma nova abordagem teórica que denominaram "a ecologia cultural". D ela originou-se a holística, abordagem confusa em suas origens teóricas, mas muito ao gosto das interpretações pouco científicas da ação pedagógica.

O funcionalismo pareceu renovado em sua fundamentação teórica ao assumir ser materialista e não simplesmente empirista e também nos seus métodos pelo uso da teoria dos sistemas.

Entretanto, precisamos constatar os limites dos trabalhos dos neo funcionalistas ligados à ecologia cultural e evidenciar sua origem. Ela reside nas insuficiências radicais de seu materialismo, que fizeram com que concebessem de maneira reducionista as relações complexas entre economia e sociedade...

Reconheçamos aí o marxismo vulgar ou economicismo, que reduz todas as relações sociais ao estatuto de epifenômenos que acompanham as relações econômicas e as reduzem a uma técnica de adaptação a um meio natural e biológico...

A racionalidade secreta das relações sociais se reduz a simples vantagens adaptativas. (GO D ELIER, 1973, p. 57).

Existem princípios comuns às três correntes e esses princípios são metodológicos, reconhecidos tanto pelo marxismo, como pelo funcionalismo e pelo estruturalismo. São considerados como condições necessárias ao estudo científico dos fatos sociais.

O primeiro estipula que é preciso avaliar as relações sociais não uma a uma separadamente, mas tomando-as em suas relações recíprocas, considerando-as como totalidades que formam sistemas. $\mathrm{O}$ segundo determina que é preciso analisar esses sistemas em sua lógica interna, antes de analisar sua gênese e evolução. De certa maneira, esses dois princípios opõem o pensamento científico moderno tanto ao evolucionismo quanto ao historicismo e difusionismo do século XX, na medida em que, malgrado suas contribuições opostas sobre a evolução das sociedades, essas doutrinas contentam-se freqüentemente com uma análise superficial do funcionamento real de

Rev. D iálogo Educ., Curitiba, v. 9, n. 26, p. 29-45, jan./ abr. 2009 
costumes e instituições sociais e consagram o essencial de seus esforços a pesquisar sua origem e retraçar a história de estágios anteriores de uma evolução puramente conjetural da humanidade. (GODELIER, 1973, p. 61).

A filosofia das ciências do século XX dificilmente acompanha as revoluções científicas que se aceleravam e apontavam para o fim dos postulados a priori da razão. 0 novo espírito científico analisa a História da razão, mas para demonstrar que ela é descontínua, cheia de obstáculos, de conflitos e de contradições.

É nesse contexto que Bachelard propõe a epistemologia histórica, pois "somente uma epistemologia que parta da reflexão da própria ciência pode tornar-se adequada para expressá-la" (BARBOSA; BULCÃO 2004, p. 20). A epistemologia de Bachelard não é singular, pois para ele cada ciência tem a sua epistemologia. 0 que a torna unitária é sua característica de aplicação, comum a todas as ciências e à racionalidade. Bachelard chama de racionalismo aplicado a sua proposta.

Ao analisar o procedimento das ciências contemporâneas, constata a existência de um novo espíito científico e percebe a necessidade de uma nova filosofia da ciência que deve se constituir contra uma concepção clássica de razão e de realidade. Na concepção do antigo espírito científico, a razão era pensada como substância, constituindo-se como algo fechado. A realidade era vista como coisa pronta e acabada; a função da ciência consistia em captar esta realidade e tentar reproduzi-la o mais fielmente possível. (BARBOSA; BULCÃO, 2004, p. 28).

Para ele, o laço pelo qual estão ligados o empirismo e o racionalismo é tão forte como o que une o prazer à dor. "Um deles triunfa justificando o outro; o empirismo necessita ser compreendido e o racionalismo necessita ser aplicado" (BACHELARD, 1966, p. 5).

A dialética que se observa na relação entre o empírico e o racional, observa-se também na relação entre a razão e a imaginação. Nesse âmbito é que podem ser estudadas as aplicações do pensamento de Bachelard à educação.

Escapando das intermináveis discussões acadêmicas sobre qual denominação devem portar as produções intelectuais, Bachelard afirma a necessidade de extrair um valor de aplicação de cada valor de racionalidade: 0 conhecimento deve ser aplicado, e particularmente aplicado. $\mathrm{O}$ u seja, a vivência é anterior à reflexão e continuamente concomitante a ela. A prioridade epistemológica é da História, enquanto realidade vivida, no cotidiano e na longa duração.

Rev. Diálogo Educ., Curitiba, v. 9, n. 26, p. 29-45, jan./ abr. 2009 
Por essa característica do conhecimento aplicado, o PDE pode ser incluído na exemplaridade de uma inversão didática que tem sua base firmemente colocada na prática profissional do professor, desde que o processo de reflexão seja instituído coletivamente em nível crítico e de aplicação.

0 conhecimento tem origem nos interesses que a humanidade mantém em relação ao mundo real. Habermas foi o autor que chegou à definição dos campos do conhecimento a partir dos interesses. Na leitura de Adela Cortina, sua teoria pode ser resumida como tendo, no âmbito da relação entre conhecimento e interesse, o seguinte quadro:

São três as perspectivas a partir das quais concebemos a realidade e três são as categorias do saber possível: informações, que ampliam a capacidade do domínio técnico; interpretações, que possibilitam uma orientação da ação sob tradições comuns; e análise, que emancipa a consciência, com respeito a forças constituídas.

A esses três tipos de perspectivas, estão subjacentes três orientações básicas do saber: 0 interesse técnico, que mantém o significado das ciências empírico-analíticas; 0 interesse prático, constitutivo do significado do domínio das ciências histórico-hermenêuticas; e 0 interesse emancipatório, que dirige a tarefa das ciências sociais críticas. Os três interesses se necessitam reciprocamente e é, portanto, inevitável que sejam mediados dialeticamente. (CORTINA, 1985, p. 117).

Os interesses cognoscitivos são para Habermas orientações básicas, inerentes a determinadas condições fundamentais da reprodução eda autodeterminação possíveis da espécie humana; quer dizer, inerentes ao trabalho e à interação.

Não se trata de interesses empíricos, individuais, e sim de interesses inerentes ao gênero humano, que se orienta por eles até chegar aos saberes necessários para sua reprodução e autoconstituição. Ao analisar a racionalidade como dimensão intrínseca à modernidade, Habermas considera a orientação das relações da espécie humana com o mundo dos objetos (trabalho) e a orientação das relações dos homens entre si (interação). Tais relações se efetivam nas ações, que ocorrem mediante os interesses.

0 interesse emancipatório desenvolve a capacidade reflexiva, de crítica da realidade, capacidade esta que se aprende pelo método do consenso racional. Nas escolas, esse método é praticado pela direção colegiada. Nas salas de aula, pelo método da sistematização coletiva dos conhecimentos. Mas no sistema educacional há resistência, porque a lógica é a do poder, não verbal e muito

Rev. D iálogo Educ., Curitiba, v. 9, n. 26, p. 29-45, jan./ abr. 2009 
menos socializada como na gestão colegiada. Também na sala de aula há resistências, porque os conhecimentos são complexos e tradicionalmente não se exercita a atitude de pesquisa e reflexão.

Com base em Habermas, a educação escolar pode ser conceituada como ação comunicativa. Tem como pressuposto o interesse emancipatório, mas não dispensa os outros interesses, tanto o técnico quanto o prático, porque trabalha com todos os conteúdos no âmbito dos conhecimentos. A ação comunicativa referese à interação de dois ou mais sujeitos, capazes de linguagem e de ação, que estabelecem uma relação interpessoal. 0 conceito central, nesse tipo de ação, é o de interpretação e se refere primordialmente à negociação de definições da situação, definições essas suscetíveis de consenso. A linguagem ocupa, neste modelo de ação, um lugar muito importante. Todos os atores são sujeitos protagonistas da ação. Cada um pode mudar a direção da construção da síntese final, que é coletiva e de consenso. Cada um pode, também, trazer novos materiais de suporte para o ensino. 0 professor dirige o processo, conduzindo o debate e interferindo nele.

Valendo-se de outros autores das teorias cognitivas de aprendizagem, especialmente Piaget, Habermas não toma 0 conceito de aprendizagem como incorporação de experiências pelos sujeitos num processo contínuo, mas sim como "um processo descontínuo de desenvolvimento das capacidades cognitivas" (COHN, 1993, p. 71). Sua teoria está centrada na capacidade reflexiva e na autonomia de pensamento dos atores da interação e da comunicação.

Esses foram os pontos que possibilitaram a aplicação da teoria da ação comunicativa, de Habermas, ao campo da aprendizagem e da educação escolar. Em nosso estudo, a teoria de Habermas, que vale dizer não é destinada ao campo da educação escolar, tem elementos que podem contribuir para a fundamentação epistemológica de Bachelard, especificamente quando considera todos os sujeitos das vivências de aprendizagem como atores do processo de ação comunicativa e da priorização da linguagem como pragmática, utilizando o argumento como 0 principal instrumento da racionalidade, no âmbito do processo de reflexão coletiva.

Não nosesqueçamos deque estamos lidando com umateoria da ação. Portanto, não se trata da linguagem sem mais, mas da linguagem em uso, dalinguagem mobilizada poratores sociais. 0 que está em jogo, quando Habermas estuda a linguagem, não éa dimensão formal das regras de relações entreos signos (uma sintática), nem mesmo a dimensão das relações entre os significantes lingüísticos e suas referências (uma semântica), mas sim a relação entre a linguagem e seus usuários (uma pragmática). E isso se faz na busca do esclarecimento das relações dos próprios usuários entre si, em redes de relações de crescente amplitude. (COHN, 1993, p. 65).

Rev. Diálogo Educ., Curitiba, v. 9, n. 26, p. 29-45, jan./ abr. 2009 
0 tripé da fundamentação que adotamos completa-se com uma das teorias cognitivas de aprendizagem, a de Vygotsky. Para esse autor, a aprendizagem pode converter-se em desenvolvimento, sendo considerada uma condição para este mesmo desenvolvimento e ao mesmo tempo uma conseqüência dele. A mediação do professor na aprendizagem cresce na sua importância, em relação às demais teorias de ensino e de aprendizagem.

Nossa proposição é que a mediação da cultura utiliza como instrumentos didáticos as ações do grupo de alunos, com a direção do professor. O método é ativo, no sentido de que todo participante do grupo vem a atuar, ainda que por alguns momentos, mediante sínteses apresentadas por ele. Temos então, nesse tripé de fundamentos: a vivência com a reflexão; a linguagem mobilizada por atores sociais; e a mediação do professor e da cultura, utilizando como instrumentos as próprias ações do grupo de alunos com as fontes de conhecimento por eles trazidas para um espaço e um tempo comuns.

O PDE enquanto proposição de gestão e organização do trabalho pedagógico vem de encontro a essa fundamentação, cumprindo os pressupostos de vivência, reflexão coletiva, intencionalidade na transformação de uma prática profissional analisada, ampliação das fontes para a aprendizagem do conhecimento e compromisso na mediação pedagógica enquanto sujeito responsável pela mediação da cultura.

Por si só, esse último ponto - a mediação - justifica o cuidado com a formação continuada do professor em exercício, em nível de pós-graduação, pois quanto menos a mediação for oferecida, menor será a capacidade de uma pessoa ser afetada e se modificar. Lembrando que a mediação é a categoria central na teoria de Vygotsky, citamos a importância da mediação da cultura, definida por Feuerstein:

A falta de mediação da cultura reduz a capacidade de alargar o campo experiencial da pessoa para além do imediato, mantendo-a no episódico e impedindo-a de aprender a aprender.

À luz dessas reflexões, Feuerstein faz uma analogia entre a idéia de transmissão cultural e 0 arco e flecha. A distância na qual a flecha vai ser projetada é uma função direta do grau de torção para trás que se dá à corda do arco. Q uanto mais a corda for puxada para trás, mais longe a flecha vai ser projetada. D a mesma maneira, quanto mais um povo sabe sobre sua cultura, mais consegue entender as possibilidades para uma mudança da realidade. (SO UZA; DEPRESBITERIS; MACHAD 0, 2004, p. 62).

Rev. D iálogo Educ., Curitiba, v. 9, n. 26, p. 29-45, jan./ abr. 2009 
A formação continuada é uma política que favorece a mediação da cultura. Sendo esta uma construção histórica e nunca acabada, uma aprendizagem mediada por sua dimensão somente pode representar maior formação humana do professor e dos estudantes. A instituição do método da reflexão coletiva, com a intencionalidade de construir consenso e transformar a prática social profissional do professor em exercício, cumpre as possibilidades da mediação da cultura na escola. Para Bachelard, o método é a antítese do hábito e para nós, a formação continuada é a antítese da estagnação.

\section{REFERÊNCIAS}

BACHELARD, G aston. Le nouvel esprit scientifique. 3. ed. Paris: PUF, 1966.

BARBO SA, Elyana; BULCÃO, Marly. Bachelard: pedagogia da razão, pedagogia da imaginação. Petrópolis, RJ: Vozes, 2004.

BERGER, Peter; LUCKMANN, Thomas. A construção social da realidade. Tratado de sociologia do conhecimento. Petrópolis, RJ: Vozes, 1973.

BRASIL. Leis e decretos federais. In: PARANÁ, SE ED / CE E. E dição atualizada até março de 2008. Curitiba: SEED / CEE, 2008.

BO SI, Alfredo. A dialética da colonização. São Paulo: Companhia das Letras, 1992.

COHN, Gabriel. A teoria da ação em Habermas. In: CARVALHO, Maria do Carmo Brandt (O rg.). Teorias da ação em debate. São Paulo: Cortez; FAPESP: Instituto de Estudos Especiais, PUC-SP, 1993.

CO RTINA, Adela. Crítica y utopía: la escuela de Francfort. Madrid: Cincel, 1985.

ESTEVE, José Manuel. 0 mal - estar docente. A sala de aula e a saúde dos professores. Bauru, SP: ED USC, 1999.

GODELIER, Maurice. Economias e sociedades: abordagens funcionalista, estruturalista e marxista. In: CARVALHO, Edgard Assis (O rg.). Antropologia econômica. São Paulo: Livraria Editora Ciências Humanas Ltda, 1978.

Rev. Diálogo Educ., Curitiba, v. 9, n. 26, p. 29-45, jan./ abr. 2009 
HABERMAS, Jürgen. Teoría de la acción comunicativa. Madrid: Taurus, 1988.

MARTINS, Pura Lúcia O liver. As formas e práticas de interação entre professores e alunos. In: VEIGA, Ilma Passos Alencastro (O rg.). Lições de didática. Campinas: Papirus, 2006. p. 75-100.

. Didática teónica/ didática prática: para além do confronto. Sã̃o Paulo: Loyola, 1989.

MO RIN, Edgar. A cabeça bem feita. Rio de Janeiro: Bertrand do Brasil, 2000.

PARANÁ. Lei Complementar no 103, de 15 de março de 2004, no Decreto no 4482/ 2005 e no Decreto no 3149/ 2004. Diário Oficial, Secretaria de Estado da Educação, n. 4341/ 2007, 17 out. 2007.

PARANÁ. D ecreto n.o 4482, de 14 de março de 2005. Diánio O ficial, Secretaria de Estado da Educação, n. 2007/ 05, 21 jul. 2005.

PARANÁ. SEED. Resoluções do secretário de estado da educação, junho de 2007. Curitiba: SEED, 2007.

PARANÁ. SUED/ SEED. Instruções normativas da Superintendência de Educação, março de 2008. Curitiba: SEED, 2008.

SOUZA, Ana Maria Martins; DEPRESBITERIS, Léa; MACHAD O, O sny Telles Marcondes. A mediação como princípio educacional: bases teóricas das abordagens de REUVEN FEUERSTE IN. São Paulo: SENAC São Paulo, 2004.

VÁSQ UEZ, Adolfo Sánchez. Filosofia da práxis. 2. ed. Rio de Janeiro: Paz e Terra, 1977.

WACHOWICZ, Lílian Anna. As tensões dialéticas na educação. In: WACHOWICZ, Lílian Anna (Org.). A interdisciplinaridade na Universidade. Curitiba: Champagnat, 1998. p. 111-125.

Recebido: 02/ 08/ 2008 Reeeived: 08/ 02/ 2008

Aprovado: 22/ 11/ 2008

A pproved: 11/ 22/ 2008

Rev. D iálogo Educ., Curitiba, v. 9, n. 26, p. 29-45, jan./ abr. 2009 